\title{
Cardiac Magnetic Resonance Analysis of Mitral Annular Dynamics after Mitral Valve Repair
}

\author{
Ahmad A. Abdouni (iD,* Carlos M.A. Brandão iD, Carlos E. Rochitte iD, Pablo M.A. Pomerantzeff(iD, \\ Elinthon T. Veronese iD, Ariane B. Pacheco iD, Antonio S. Santis, Flávio Tarasoutchi iD, Fábio B. Jatene iD \\ Instituto do Coracao (InCor), Hospital das Cinicas (HCFMUSP), Faculdade de Medicina, Universidade de Sao Paulo, Sao Paulo, SP, BR. \\ Abdouni AA, Brandão CMA, Rochitte CE, Pomerantzeff PMA, Veronese ET, Pacheco AB, et al. Cardiac Magnetic Resonance Analysis of Mitral Annular \\ Dynamics after Mitral Valve Repair. Clinics. 2020;75:e2428 \\ *Corresponding author. E-mail: dr.ahmad@ig.com.br
}

\begin{abstract}
OBJECTIVES: The aim of this study was to analyze mitral annulus (MA) dynamics using cardiac magnetic resonance (CMR) in patients with degenerative mitral insufficiency who underwent mitral valve repair (MVR). METHODS: Mitral valve imaging was performed by CMR in twenty-nine patients with degenerative mitral insufficiency who underwent MVR between July 2014 and August 2016, with quadrangular resection of the posterior leaflet without ring annuloplasty. They were prospectively followed up from the preoperative period up to 2 years postoperatively.

RESULTS: We observed a significant reduction in all measurements of the MA after surgery. The mean systolic circumference of the MA was reduced from $13.28 \pm 1.95 \mathrm{~cm}$ to $11.50 \pm 1.59 \mathrm{~cm}$, and the diastolic circumference was reduced from $12.51 \pm 2.01 \mathrm{~cm}$ to $10.66 \pm 2.09 \mathrm{~cm}$ in the immediate postoperative period, measures that remained stable 2 years after MVR $(p<0.001)$. The mean maximum area of the MA was significantly reduced from $14.34 \pm 4.03$ to $10.45 \pm 3.17 \mathrm{~cm}^{2}$ when comparing the immediate postoperative period and the 2 year follow-up $(p<0.001)$. The same occurred with the mean minimum area of the MA, which was reduced from $12.53 \pm 3.68 \mathrm{~cm}^{2}$ to $9.23 \pm 2.84 \mathrm{~cm}^{2}$ in the same period, and this reduction was greater in the antero-posterior diameter than in the mid-lateral diameter. The mobility of the MA was preserved after surgery, ranging between $19.6 \%$ and $25.7 \%$ at 2-year follow-up.
\end{abstract}

CONCLUSION: We observed a significant reduction in the MA size after MVR, with preservation of the MA mobility at the 2-year follow-up.

KEYWORDS: Cardiac Magnetic Resonance; Mitral Valve Insufficiency; Mitral Valve Repair.

\section{INTRODUCTION}

Mitral valve repair (MVR) is the treatment of choice for degenerative mitral regurgitation, presenting lower rates of thromboembolism and endocarditis, reduced need for anticoagulation, excellent survival and durability in long-term follow-up, and better left ventricular function, when compared with mitral valve (MV) replacement (1).

Recent studies have demonstrated that cardiac magnetic resonance (CMR) can accurately demonstrate variations in measurements and shape of the mitral annulus (MA) during the cardiac cycle $(2,3)$.

There is little data in the literature regarding the remodeling and dynamics of the mitral annulus during the postoperative period of MVR. The present study describes aspects of the

Copyright $\odot 2020$ CLINICS - This is an Open Access article distributed under the terms of the Creative Commons License (http://creativecommons.org/licenses/by/ 4.0/) which permits unrestricted use, distribution, and reproduction in any medium or format, provided the original work is properly cited.

No potential conflict of interest was reported.

Received for publication on September 15, 2020. Accepted for publication on September 24, 2020

DOI: $10.6061 /$ clinics/2020/e2428 morphology and functioning of the MA over the course of a 2-year postoperative period, in a population with degenerative mitral regurgitation, with the use of $C M R$ imaging to evaluate dimensions and mobility of the MA after MVR.

\section{MATERIAL AND METHODS}

The present study was conducted at the Heart Institute of the University of São Paulo Medical School. The study protocol was approved by the Institutional Ethics Committee, and all patients provided written informed consent prior to the surgery.

Patients with multiple valvopathies, previous cardiac surgery, coronary artery disease, or those undergoing emergency surgery were excluded. From July 2014 to August 2016, 29 patients underwent MVR with the "Double Teflon" technique, which consists of the quadrangular resection of the prolapsed segment of the posterior leaflet, followed by annulus plication of the correspondent segment, reinforced with "pledget" stitches over the Teflon patch (4). All patients were studied by CMR through a specific protocol in the preoperative period, immediate postoperative period, and after 6 months, 1 year, and 2 years of follow-up. All procedures were performed by the same surgical team, and all examinations were also monitored by the same medical team. 
CMR studies were performed using a clinical $1.5 \mathrm{~T}$ scanner (Philips Achieva-Philips HealthCare, Best, Netherlands) using a phased-array receiver coil during breath-hold and electrocardiographic trigger. CMR images were acquired in multiple short-axis, long-axis-, and 3-chamber views in the standard format. Additional images were obtained specifically for better visualization of the MV annulus. We used 3 images for visualization of the MV on the long-axis view, with images of two chambers, three chambers, and four chambers. Using the insertion points of the MV as references in these three projections, we obtained an adequate alignment to generate the short-axis images of the MV annulus (Figure 1). We measured the antero-posterior (AP) and midlateral (ML) diameters of the MA as well as the circumference and the area of the MV annulus (Figure 2). All these measurements were obtained over four phases of the cardiac cycle: late diastole (D), early systole (S1), mid systole (S2), and late systole (S3), in order to assess the MA contractility.
Baseline characteristics and clinical outcomes are presented as absolute and relative values (percentage) for categorical values and mean and standard deviation for continuous measurements. The CMR continuous variables were compared preoperatively, and postoperatively at 30 days, 6 months, 1 year, and 2 years, using analysis of variance test with repeated measures. The software used for the analysis was SPSS 21.0 for Windows (5). The level of significance used for the tests was $p<0.05$

The mean age was 63.3 years (range, $40-81$ years), and 17 patients were male $(58.6 \%)$. The mean estimated surgical risk by STS Score was $1.13 \%$ (range, $0.35-4.9$ ). Patient characteristics are presented in Table 1.

The mean cardiopulmonary bypass time was 66 minutes (range, 50-79 minutes), and the mean aortic cross-clamp time was 47 minutes (range, 36-58 minutes). The associated technique of MVR, the chordal shortening of the anterior leaflet, was used in five patients $(17.2 \%)$.

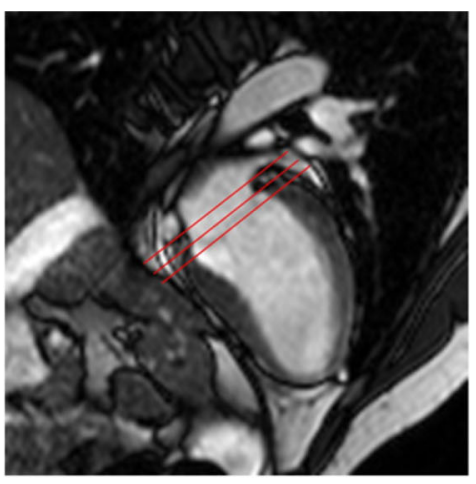

A
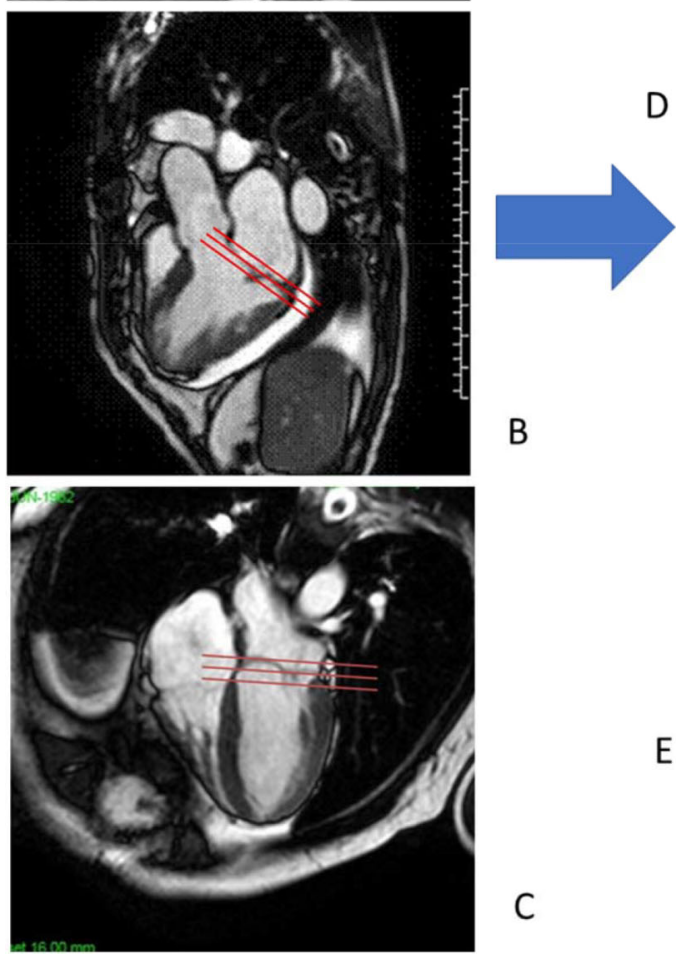
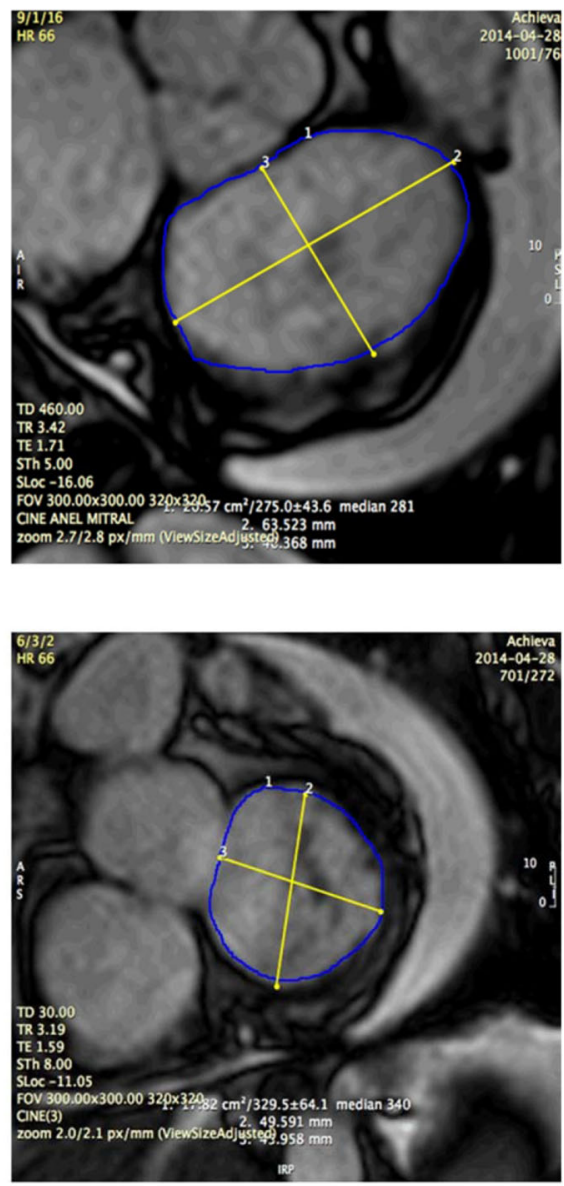

Figure 1 - Acquisition of mitral valve images by CMR. We used three images for visualization of the mitral valve on the long axis, with images in two chambers (A), 3 chambers (B) and four chambers (C). Mitral valve insertion points were visualized in all of them and used as parameters to obtain an adequate alignment and to derive the images on the short axis of the mitral valve in systole (D) and diastole (E). 


\section{A: Antero-posterior diameter measurement}
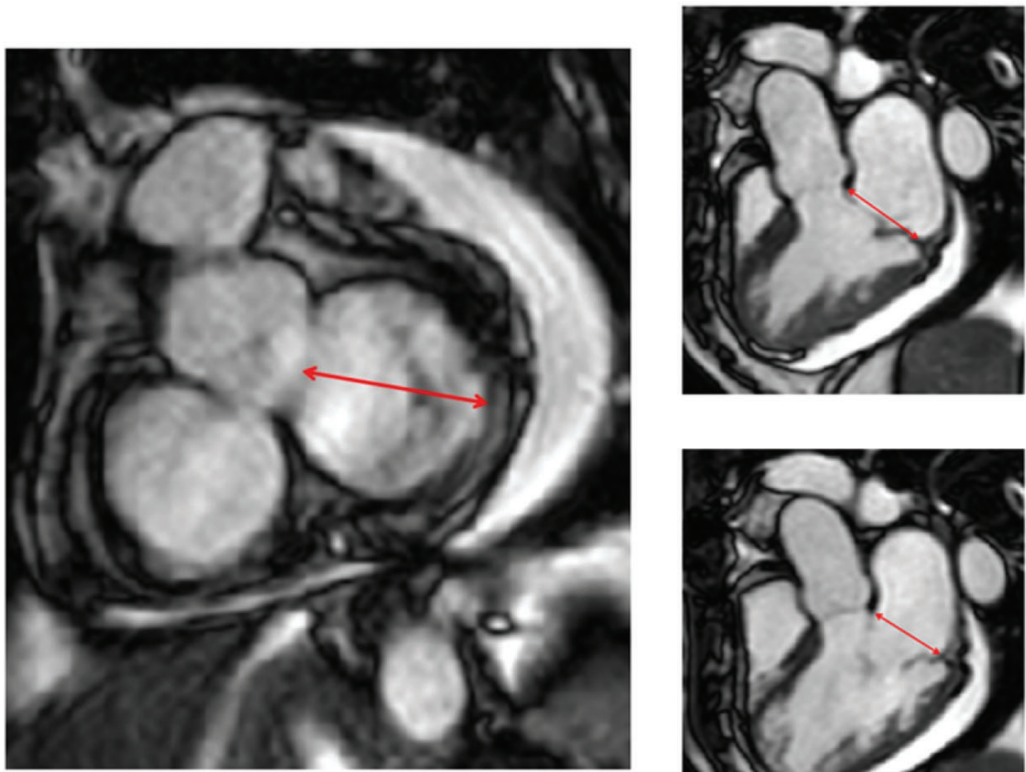

\section{Systole}

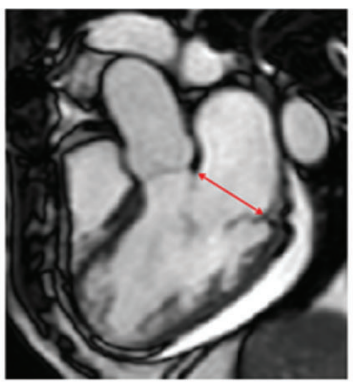

Diastole

\section{B: Mid-lateral diameter measurement}
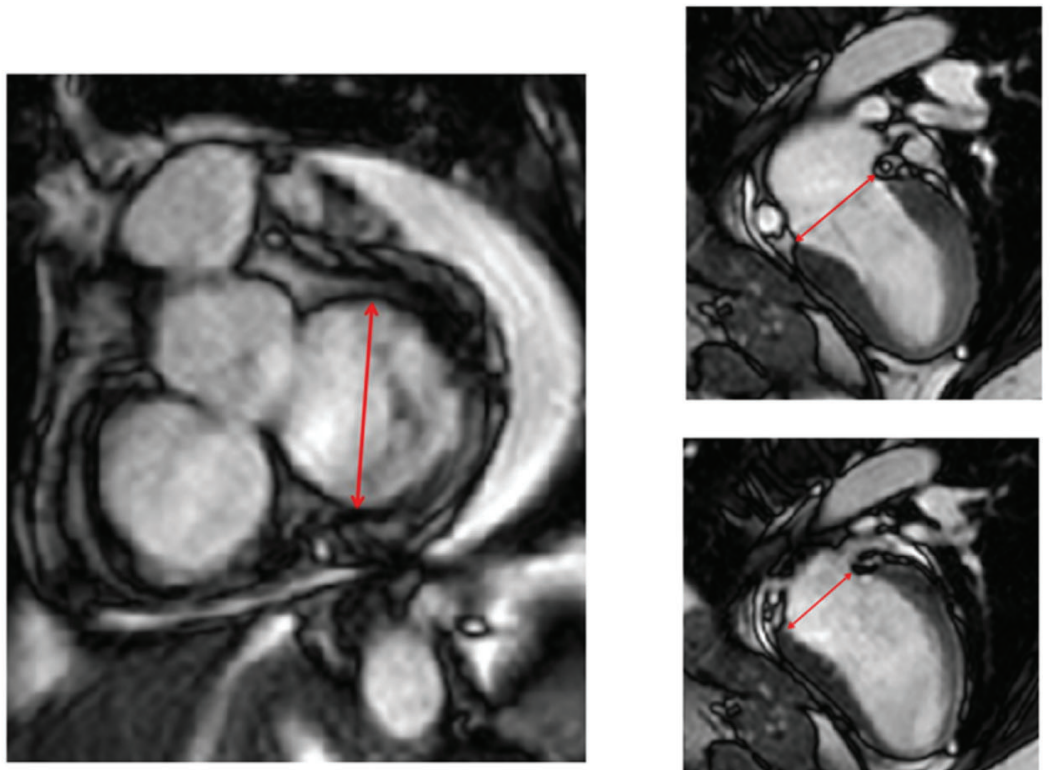

Systole

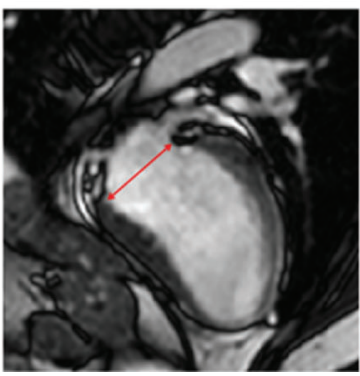

Diastole

Figure 2 - Simultaneous imaging of the short and long axis grant for measurements of annular diameters. A: Measurement of the antero-posterior diameter of the mitral annulus in the short axis derives an image in three chambers in the long axis, where the mitral valve insertion limits and insertion points are adjusted and checked. B: Measurement of mid-lateral diameter derives two-chamber images on long axis.

Regarding the operative mitral anatomic findings, there was isolated prolapse of the P2 segment of the posterior leaflet in 19 patients $(65.5 \%)$, isolated prolapse of P3 in 2 patients $(6.9 \%)$, and one patient $(3.5 \%)$ had isolated P1 prolapse. Seven patients $(24.1 \%)$ had prolapse of two segments. 


\section{RESULTS}

There was one operative death (3.4\%) secondary to acute cholecystitis and peritonitis. The remaining 28 patients were clinically reassessed at 6 months, 1 year, and 2 years postoperatively, when the follow-up CMR analysis was performed.

In the late clinical follow-up, two patients presented with embolic events (one stroke and one myocardial infarction), both successfully treated with anticoagulation. One patient presented with complete atrioventricular block 18 months after surgery and underwent pacemaker implantation. There were two late deaths $(7.1 \%)$, both from non-cardiac causes. At the 2-year follow-up, $75 \%$ of the patients were in functional class I and $25 \%$ were in functional class II (NYHA).

We observed a significant decrease in MA circumference after surgery, the mean systolic and diastolic circumference significantly decreased to $11.5 \mathrm{~cm}$ and $10.66 \mathrm{~cm}$, respectively and, at the 2-year follow-up, the MA circumference was 11.60 $\mathrm{cm}$ and $10.76 \mathrm{~cm}$ in systole and diastole, respectively $(p<0.001)$. In the analysis of the MA area, a significant reduction in the mean minimum and mean maximum area of the MA was observed after MVR, remaining after 2 years of

Table 1 - Patients Characteristics.

\begin{tabular}{lrr}
\hline Gender & N & $\%$ \\
\hline Gender & & \\
Male & 17 & 58.6 \\
Female & 12 & 41.4 \\
Preoperative Functional Class (NYHA) & & \\
Class I & 1 & 3.4 \\
Class II & 5 & 17.3 \\
Class III & 19 & 65.5 \\
Class IV & 4 & 13.8 \\
Cardiac Rhythm on Admission & & \\
Sinus & 21 & 71.4 \\
Atrial fibrillation & 8 & 27.6 \\
Comorbidities & & \\
Hypertension & 18 & 69.0 \\
Diabetes & 3 & 10.3 \\
Dyslipidemia & 10 & 34.5 \\
\hline
\end{tabular}

Values are expressed as absolute and relative frequencies (\%) for categorical values.

NYHA: New York Heart Association. follow-up $(p<0.001)$. We observed a decrease in both AP and ML diameters in all periods, and these remained stable during the 2 years of follow-up. Reduction was greater in the $\mathrm{AP}$ diameter, ranging from 18.04 to $21.76 \%$. In the $\mathrm{ML}$ diameter, the reduction ranged from $7.8 \%$ to $9.9 \%$ (Table 2).

MA mobility was assessed by the variability of MV area over the cardiac cycle. There was no statistical difference between these measurements $(p=0.572)$, as presented in Table 3.

\section{DISCUSSION}

There are several surgical techniques to correct mitral insufficiency, including interventions on the chordae tendineae, on the leaflets, on the papillary muscles, and on the MA (6). Evidence has emerged regarding the benefits of preserving the mitral annulus physiology avoids changes in intraventricular blood flow and subsequently avoids left ventricular dysfunction. In addition, the use of prosthetic rings may interfere with the physiologic mobility of the MA, changing the saddle shape, making the annulus flatter and fastening it (7). In an experimental study using CMR for flow analysis, Witschey et al. demonstrated that prosthetic rings modify the intraventricular blood flow, which can lead to left ventricular dysfunction (8). Komoda et al. demonstrated that the maintenance of MA mobility is closely related to the preservation of ventricular function. In patients who underwent annuloplasty without the use of a prosthetic ring, the MA dynamics and contraction of the base of the heart were similar to those of normal individuals (9). There is also evidence that the displacement and contractility of the atrioventricular plane can be responsible for approximately $60 \%$ of the systolic volume in adults (10).

Existing published literature shows that during MVR in degenerative disease, in cases of isolated prolapse of the posterior leaflet, the "Double Teflon" technique is sufficient to repair the MV, with good long-term clinical outcomes (11). Patients with single segment prolapse of the posterior leaflet represented $75.8 \%$ of our series, and isolated P2 prolapse was the most common defect observed, accounting for $65.5 \%$ of our sample. In a review carried out by Fundarò et al., 13 publications of mitral annuloplasty without prosthetic rings were analyzed, and they observed good outcomes,

Table 2 - Measurements of mitral annulus circumference, performed in end diastole (D) and end systole (S) and mitral valve area and antero-posterior (AP) and medial-lateral (ML) diameters of the mitral annulus, performed in diastole (D) and during the three phases of systole (S1, S2, S3).

\begin{tabular}{|c|c|c|c|c|c|c|c|}
\hline & & PRE-OP & 30 DAYS & 6 MONTHS & 1 YEAR & 2 YEARS & $p$ \\
\hline \multirow[t]{2}{*}{ Mitral Annulus Circumference $(\mathrm{cm})$} & $\mathrm{D}$ & $12.51( \pm 2.01)$ & $10.66( \pm 2.09)$ & $10.88( \pm 1.66)$ & $11.14( \pm 2.82)$ & $10.76( \pm 1.61)$ & $<0.001$ \\
\hline & $S$ & $13.28( \pm 1.95)$ & $11.50( \pm 1.59)$ & $11.59( \pm 1.72)$ & $11.69( \pm 1.99)$ & $11.60( \pm 2.18)$ & $<0.001$ \\
\hline \multirow[t]{4}{*}{ Mitral Valve Area $\left(\mathrm{cm}^{2}\right)$} & $\mathrm{D}$ & $12.77( \pm 3.72)$ & $9.77( \pm 2.38)$ & $9.65( \pm 2.85)$ & $9.58( \pm 3.63)$ & $9.39( \pm 2.81)$ & $<0.001$ \\
\hline & S1 & $12.53( \pm 3.68)$ & $9.60( \pm 2.44)$ & $9.66( \pm 2.90)$ & $9.60( \pm 3.73)$ & $9.23( \pm 2.84)$ & $<0.001$ \\
\hline & $\mathrm{S} 2$ & $13.85( \pm 4.05)$ & $10.09( \pm 2.44)$ & $10.70( \pm 3.25)$ & $10.43( \pm 3.71)$ & $10.14( \pm 2.94)$ & $<0.001$ \\
\hline & S3 & $14.34( \pm 4.03)$ & $10.72( \pm 2.81)$ & $10.92( \pm 3.06)$ & $10.98( \pm 3.45)$ & $10.45( \pm 3.17)$ & $<0.001$ \\
\hline \multirow[t]{4}{*}{ Antero-posterior Diameter (mm) } & $\mathrm{D}$ & $38.25( \pm 9.79)$ & $31.31( \pm 6.92)$ & $31.01( \pm 7.00)$ & $30.66( \pm 10.97)$ & $30.35( \pm 6.44)$ & $<0.001$ \\
\hline & S1 & $37.80( \pm 9.41)$ & $30.98( \pm 7.16)$ & $30.79( \pm 6.86)$ & $30.67( \pm 10.84)$ & $30.07( \pm 6.40)$ & $<0.001$ \\
\hline & $\mathrm{S} 2$ & $40.40( \pm 9.84)$ & $32.58( \pm 6.96)$ & $33.58( \pm 7.27)$ & $33.70( \pm 10.73)$ & $32.44( \pm 5.88)$ & $<0.001$ \\
\hline & S3 & $42.95( \pm 9.98)$ & $34.30( \pm 6.88)$ & $34.54( \pm 6.91)$ & $35.04( \pm 10.19)$ & $33.60( \pm 6.75)$ & $<0.001$ \\
\hline \multirow[t]{4}{*}{ Medial-lateral Diameter (mm) } & $\mathrm{D}$ & $42.23( \pm 5.82)$ & $39.77( \pm 5.52)$ & $39.15( \pm 5.90)$ & $39.57( \pm 5.16)$ & $38.94( \pm 5.35)$ & $=0.005$ \\
\hline & S1 & $41.99( \pm 5.42)$ & $39.41( \pm 5.40)$ & $39.50( \pm 5.90)$ & $39.54( \pm 5.28)$ & $38.53( \pm 5.49)$ & $=0.004$ \\
\hline & $\mathrm{S} 2$ & $43.50( \pm 5.16)$ & $39.46( \pm 6.24)$ & $40.05( \pm 6.44)$ & $39.28( \pm 5.80)$ & $39.19( \pm 5.46)$ & $<0.001$ \\
\hline & S3 & $42.23( \pm 5.51)$ & $39.55( \pm 6.31)$ & $39.83( \pm 6.13)$ & $39.81( \pm 5.14)$ & $38.94( \pm 5.21)$ & $=0.004$ \\
\hline
\end{tabular}

Data are expressed as mean \pm standard deviation; $p$ values refer to comparisons between all four postoperative periods versus the preoperative period. $D$ : diastole, S1: initial systole, S2: mid-systole, S3: final systole, PRE-OP: preoperative period. 
Table 3 - Measurements of variability of mitral valve area during the periods of the study.

\begin{tabular}{lcccrrr}
\hline Mitral Valve Area Variability (\%) & PRE-OP & 30 DAYS & 6 MONTHS & 1 YEAR & 2 YEARS & P \\
\hline Minimum & 7.80 & 5.30 & 6.40 & 2.50 & 3.10 \\
Maximum & 47.40 & 30.00 & 40.60 & 42.00 & 52.20 \\
Mean & 23.31 & 19.63 & 23.75 & 25.75 & 22.66 \\
SD & 9.04 & 7.01 & 8.09 & 11.27 & 9.77 \\
\hline
\end{tabular}

PRE-OP: preoperative period; SD: standard deviation.

reproducibility and cost efficiency (12). In a recent publication, Garatti et al. compared two techniques of MVR: posterior annuloplasty with a flexible ring and double suture in the posterior annulus. Both techniques were associated with similar mortality, clinical outcomes, recurrence of regurgitation, and readmission rates in 11 years of follow-up (13).

In our series, we observed a significant reduction in MA circumference after MVR. At the 2 year follow-up, the MA circumference was $11.60 \mathrm{~cm}$ in systole and $10.76 \mathrm{~cm}$ in diastole, with a reduction of $12.65 \%$ and $13.98 \%$, respectively, compared to preoperative measurements $(p<0.001)$. Similar results were observed for the MA area. In the preoperative period, the mean area of the annulus ranged from $12.6 \mathrm{~cm}^{2}$ to $14.3 \mathrm{~cm}^{2}$ over the cardiac cycle, which demonstrates greater measurements compared to the normal values described in the literature $(2,14,15)$. In the immediate postoperative period, there was a significant reduction of MV area in relation to the preoperative period $(p<0.001)$, and this reduction remained significant for up to 2 years of followup, when the area varied from $9.23 \mathrm{~cm}^{2}$ to $10.45 \mathrm{~cm}^{2}$, demonstrating the stability of MV repair in our follow-up. This reduction was significant in both the AP and ML diameters $(p<0.001)$ in the immediate and late postoperative period; the reduction was more evident in the AP diameter, which was $19-21 \%$ smaller after 2 years of follow-up than in the preoperative period. It is important to emphasize the stability of the MA measurements after MVR in all analyzed parameters, using this technique of MVR.

An important finding in the follow-up period was the maintenance of mitral annular dynamics. Despite the reduction in area, the mobility of the MA during the cardiac cycle remained at the same degree observed in the preoperative period. In the preoperative period, the mean variation in the MA during the cardiac cycle was $23.3 \%$, similar to the measures observed at the two year follow-up $(p=0.572)$, demonstrating that the MA dynamics were preserved with this surgical technique. The annulus dynamics and their morphological changes have recently become a component in advanced cardiac function analysis, as MV motion can indicate regional and global motion (16). Previous studies have already used $2 \mathrm{D}$ and $3 \mathrm{D}$ echocardiograms to analyze the behavior of the MA, and recent studies have demonstrated that CMR can accurately demonstrate variations in the measurements and shape of the MA during the cardiac cycle. Some authors have demonstrated that the MA reaches its greatest circumference and area at the end of systole, when the annulus becomes flatter and partially loses its saddle configuration. This dynamic of the MA is responsible for the reduction of hemodynamic stress imposed on the MV leaflets during the cardiac cycle (17). As in our study, other series reported similar results, with an increase in the MA area during systole related to the increase in the AP diameter $(2,18,19)$.

Decloedt et al. demonstrated that delay in ring mobility results in modification of the flow dynamics and failure of coaptation of MV leaflets (20). The maintenance of MA mobility has been closely related to preservation of ventricular function and is directly proportional to left ventricular ejection fraction (2). The finding of reduced MA mobility enabled us to predict the presence of MV dysfunction and left ventricular dysfunction, with high sensitivity and specificity, and the use of flexible rings in the surgical correction did not preserve the MA dynamics $(16,21)$. Another study demonstrated that the injury to annulus mobility was greater in techniques with greater resection of the leaflets and segmental aplications, followed by prosthetic ring annuloplasty (22). A patient-specific finite element model using CMR images has been used to individualize MVR, simulating the results of artificial chordal implantation and leaflet resection with annuloplasty, and can be useful to predict the results in ventricular and annulus dynamics $(23,24)$.

CMR is a useful tool to detect myocardial fibrosis, which is associated with a higher incidence of arrhythmias in patients with MR and is an independent predictor of increased incidence of adverse clinical outcomes in patients undergoing MVR (25). The type and extent of myocardial fibrosis correlated with the remodeling of the left ventricle in the clinical and postoperative context of MV disease $(26,27)$. MA abnormalities have been correlated with increased presence of fibrosis, arrhythmias, and ventricular dysfunction in studies with CMR (28), demonstrating the importance of preservation of mitral annular mobility in the treatment of MR.

\section{CONCLUSIONS}

CMR was able to accurately demonstrate the measurements and dynamics of the MA in the pre- and postoperative periods of MVR. We observed a significant reduction in size of the MA after MVR, with preservation of MA contractility and valve repair stability at the 2 year follow-up, using a technique of MVR without ring implantation.

\section{ACKNOWLEDGMENTS}

Supported by FAPESP (Fundação de Amparo à Pesquisa do Estado de São Paulo) Grants 2014/05391-0

\section{AUTHOR CONTRIBUTIONS}

Abdouni AA contributed in investigation, data curation, writing-original draft and writing-review \& editing. Brandão CM contributed in investigation, data curation, writing-original draft, writing-review \& editing and project administration. Rochitte $\mathrm{CE}$ contributed in resources and data curation. Pomerantzeff PM contributed in conceptualization, investigation and supervision. Veronese ET contributed in investigation and writingreview \& editing. Pacheco $\mathrm{AB}$ contributed in investigation. Santis AS contributed in investigation. Tarasoutchi $\mathrm{F}$ contributed in supervision. Jatene FB contributed in supervision and investigation. 


\section{REFERENCES}

1. Shuhaiber J, Anderson RJ. Meta-analysis of clinical outcomes following surgical mitral valve repair or replacement. Eur J Cardiothorac Surg. 2007;31(2):267-75. https://doi.org/10.1016/j.ejcts.2006.11.014

2. Leng S, Zhang S, Jiang M, Zhao X, Wu R, Allen J, et al. Imaging 4D morphology and dynamics of mitral annulus in humans using cardiac cine MR feature tracking. Sci Rep. 2018;8(1):81. https://doi.org/10.1038/ s41598-017-18354-2

3. Heitner J, Bhumireddy GP, Crowley AL, Weinsaft J, Haq SA, Klem I, et al. Clinical application of cine-MRI in the visual assessment of mitral regurgitation compared to echocardiography and cardiac catheterization. PLoS One. 2012;7(7):e40491. https://doi.org/10.1371/journal.pone.00 40491

4. Pomerantzeff PM, Brandão CM, Souza LR, Vieira ML, Grimberg M, Ramires JA, et al. Posterior mitral leaflet repair with a simple segmental annulus support: the 'double-Teflon technique'. J Hear Valve Dis. 2002; 11(2):160-4.

5. IBM SPSS Statistics for Windows, Version 21.0. Armonk, NY: IBM Corp.

6. Verma S, Mesana TG. Mitral valve repair for mitral-valve prolapse. N Engl J Med. 2009;361(23):2261-9. https://doi.org/10.1056/NEJMct080 6111

7. Dagum P, Green GR, Glasson JR, Daughters GT, Bolger AF, Foppiano LE, et al. Potential mechanism of left ventricular outflow tract obstruction after mitral ring annuloplasty. J Thorac Cardiovasc Surg. 1999;117(3):47280. https: / /doi.org/10.1016/S0022-5223(99)70326-0

8. Witschey WR, Zhang D, Contijoch F, McGarvey JR, Lee M, Takebayashi S, et al. The Influence of Mitral Annuloplasty on Left Ventricular Flow Dynamics. Ann Thorac Sur. 2015;100(1):114-21. https://doi.org/10.1016/ j.athoracsur.2015.02.028

9. Komoda T, Hetzer R, Siniawski H, Huebler M, Felix R, Maeta H. Mitral annulus after mitral repair: geometry and dynamics. ASAIO J. 2002; 48(4):412-8. https://doi.org/10.1097/00002480-200207000-00016

10. Carlsson M, Ugander M, Mosén H, Buhre T, Arheden H. Atrioventricular plane displacement is the major contributor to left ventricular pumping in healthy adults, athletes, and patients with dilated cardiomyopathy. Am J Physiol Hear Circ Physiol. 2007;292(3):H1452-9. https:/ /doi.org/10.1152/ ajpheart.01148.2006

11. Brandão CM, Guedes MA, Silva MF, Vieira ML, Pomerantzeff PM, Stolf NA. Mitral valve repair with "Double Teflon" technique: 10-year results. Rev Bras Cir Cardiovasc. 2007;22(4):448-53. https://doi.org/10.1590/ S0102-76382007000400011

12. Fundarò P, Tartara PM, Villa E, Fratto P, Campisi S, Vitali EO. Mitral valve repair: Is there still a place for suture annuloplasty? Asian Cardiovasc Thorac Ann. 2007;15(4):351-8. https://doi.org/10.1177/021849230701 500420

13. Garatti A, Canziani A, Parolari A, Castelvecchio S, Guazzi M, Daprati A, et al. Long-term results of suture annuloplasty for degenerative mitral valve disease: a propensity-matched analysis. J Cardiovasc Med. 2018; 19(1):22-8. https://doi.org/10.2459/JCM.0000000000000608

14. Ben Zekry S, Jain S, Alexander SK, Li Y, Aggarwal A, Jajoo A, et al. Novel parameters of global and regional mitral annulus geometry in man: comparison between normals and organic mitral regurgitation, before and after mitral valve repair. Eur Heart J Cardiovasc Imaging. 2016;17(4): 447-57. https://doi.org/10.1093/ehjci/jev187

15. Pouch AM, Vergnat M, McGarvey JR, Ferrari G, Jackson BM, Sehgal CM, et al. Statistical assessment of normal mitral annular geometry using automated three-dimensional echocardiographic analysis. Ann Thorac Surg. 2014;97(1):71-7. https://doi.org/10.1016/j.athoracsur.2013. 07.096
16. Qin JX, Shiota T, Tsujino H, Saracino G, White RD, Greenberg NL, et al. Mitral annular motion as a surrogate for left ventricular ejection fraction: real-time three-dimensional echocardiography and magnetic resonance imaging studies. Eur J Echocardiogr. 2004;5(6):407-15. https://doi.org/ 10.1016/j.euje.2004.03.002

17. Salgo IS, Gorman JH 3rd, Gorman RC, Jackson BM, Bowen FW, Plappert $\mathrm{T}$, et al. Effect of annular shape on leaflet curvature in reducing mitral leaflet stress. Circulation. 2002;106(6):711-7. https://doi.org/10.1161/01. CIR.0000025426.39426.83

18. Kwan J, Qin JX, Popovi ZB, Agler DA, Thomas JD, Shiota T. Geometric changes of mitral annulus assessed by real-time 3-dimensional echocardiography: Becoming enlarged and less nonplanar in the anteroposterior direction during systole in proportion to global left ventricular systolic function. J Am Soc Echocardiogr. 2004;17(11):1179-84. https://doi. org/10.1016/j.echo.2004.06.027

19. Mih il S, Muraru D, Piasentini E, Miglioranza MH, Peluso D, Cucchini U, et al. Quantitative analysis of mitral annular geometry and function in healthy volunteers using transthoracic three-dimensional echocardiography. J Am Soc Echocardiogr. 2014;27(8):846-57. https://doi.org/ 10.1016/j.echo.2014.04.017

20. Decloedt A, Verheyen T, Sys S, De Clercq D, Bijnens B, van Loon G. Influence of atrioventricular interaction on mitral valve closure and left ventricular isovolumic contraction measured by tissue Doppler imaging. Circ Cardiovasc Imaging. 2013;6(1):109-16. https://doi.org/10.1161/ CIRCIMAGING.112.978692

21. Levack MM, Jassar AS, Shang EK, Vergnat M, Woo YJ, Acker MA, et al. Three-dimensional echocardiographic analysis of mitral annular dynamics: implication for annuloplasty selection. Circulation. 2012; 126(11 SUPPL.1):S183-8. https://doi.org/10.1161/CIRCULATIONAHA.111. 084483

22. Ben Zekry S, Lang RM, Sugeng L, McCulloch ML, Weinert L, Raman J, et al. Mitral annulus dynamics early after valve repair: preliminary observations of the effect of resectional versus non-resectional approaches. J Am Soc Echocardiogr. 2011;24(11):1233-42. https://doi.org/ 10.1016/j.echo.2011.08.010

23. Sturla F, Onorati F, Votta E, Pechlivanidis K, Stevanella M, Milano AD, et al. Is it possible to assess the best mitral valve repair in the individual patient? Preliminary results of a finite element study from magnetic resonance imaging data. J Thorac Cardiovasc Surg. 2014;148(3):1025-34. https://doi.org/10.1016/j.jtcvs.2014.05.071

24. Ge L, Morrel WG, Ward A, Mishra R, Zhang Z, Guccione JM, et al. Measurement of mitral leaflet and annular geometry and stress after repair of posterior leaflet prolapse: virtual repair using a patient-specific finite element simulation. Ann Thorac Surg. 2014;97(5):1496-503. https:/ / doi.org/10.1016/j.athoracsur.2013.12.036

25. Kitkungvan D, Nabi F, Kim RJ, Bonow RO, Khan MA, Xu J, et al. Myocardial Fibrosis in Patients With Primary Mitral Regurgitation With and Without Prolapse. J Am Coll Cardiol. 2018;72(8):823-34. https://doi.org/ 10.1016/j.jacc.2018.06.048

26. Chaikriangkrai K, Lopez-Mattei JC, Lawrie G, Ibrahim H, Quinones MA, Zoghbi W, et al. Prognostic value of delayed enhancement cardiac magnetic resonance imaging in mitral valve repair. Ann Thorac Surg. 2014; 98(5):1557-63. https://doi.org/10.1016/j.athoracsur.2014.06.049

27. Levine RA, Jerosch-Herold M, Hajjar RJ. Mitral Valve Prolapse: A Disease of Valve and Ventricle. J Am Coll Cardiol. 2018;72(8):835-7. https://doi. org/10.1016/j.jacc.2018.07.006

28. Perazzolo Marra M, Basso C, De Lazzari M, Rizzo S, Cipriani A, Giorgi B, et al. Morphofunctional Abnormalities of Mitral Annulus and Arrhythmic Mitral Valve Prolapse. Circ Cardiovasc Imaging. 2016;9(8):e005030. https://doi.org/10.1161/CIRCIMAGING.116.005030 